\title{
VALIDATION OF RIPASA SCORING SYSTEM FOR THE DIAGNOSIS OF ACUTE APPENDICITIS
}

\author{
H. C. Srikantaiah ${ }^{1}$, Arvind Nayak $K^{2}$
}

${ }^{1}$ Associate Professor, Department of General Surgery, M. S. Ramaiah Medical College, Bangalore.

${ }^{2}$ Senior Resident, Department of Urology, M. S. Ramaiah Medical College, Bangalore.

\section{ABSTRACT}

Acute appendicitis is one of the most common surgical emergencies. The diagnosis of acute appendicitis is based on clinical history, examination combined with investigations. A delay in performing an appendectomy increases the risk of developing perforation and sepsis. The opposite is also true wherewith decreased diagnostic accuracy, the negative appendectomy rates increase. Ultrasonography and Computerized Tomography help in confirming the diagnosis; however, they are expensive and sometimes inaccessible.

Several scoring systems have been developed to help in the diagnosis of appendicitis namely Alvarado and modified Alvarado scoring system. A new RIPASA (Raja Isteri Penigiran Anak Saleha) scoring system was developed to aid in the diagnosis of acute appendicitis in Asian countries. The purpose of this study is to validate the scoring system in our setup.

\section{KEYWORDS}

Right Iliac Fossa Pain Abdomen, Acute Appendicitis, Appendectomy, RIPASA (Raja Isteri Penigiran Anak Saleha) Scoring System.

HOW TO CITE THIS ARTICLE: H. C. Srikantaiah, Arvind Nayak K. "Validation of RIPASA Scoring System for the Diagnosis of Acute Appendicitis." Journal of Evolution of Medical and Dental Sciences 2015; Vol. 4, Issue 100, December 14; Page: 16533-16547, DOI: $10.14260 /$ jemds/2015/2461

\section{INTRODUCTION}

"Diagnosis of Appendicitis is usually easy" thus wrote Sir Zachary Cope, but with the order, "But there are difficulties which need to be discussed." The "Difficulty" alluded to by Cope relates to our inability to reliably diagnose appendicitis on clinical ground. ${ }^{1}$

Nothing can be so easy or as difficult as the diagnosis of acute appendicitis. Acute appendicitis is a common cause of abdominal pain, for which a prompt diagnosis is rewarded by a marked decrease in morbidity and mortality. ${ }^{2}$

The question, does this patient have appendicitis?, is an important question for the following reasons:

- Appendicitis is one of the common causes of abdominal pain.

- Western literature report that $6 \%$ of populations have risk of suffering from appendicitis during their lifetime. ${ }^{3}$

- The mortality rate has dropped due to early surgical intervention and antibiotics from $26 \%$ to less than $1 \%$.

- The morbidity due to perforation ranges from $17-40 \%$, the perforation rate is higher in elderly and children. ${ }^{4,5}$

- Failure to diagnose early appendicitis converts acute appendicitis to perforated appendicitis, a disease with potential complication including abdominal wall abscesses, wound infection and death. ${ }^{6}$

- The negative laparotomy ranges from $15-35 \%$ and is associated with significant morbidity.4,5

The routine diagnosis of appendicitis is by eliciting typical history of migrating abdominal pain followed by anorexia and nausea. Physical examination reveals tenderness in right iliac fossa and rebound tenderness.

The routine laboratory examination of blood and urine is necessary to rule out other causes of right iliac fossa pain. $\mathrm{C}$ reactive protein may be used to assist in the diagnosis of appendicitis. 7,8

Financial or Other, Competing Interest: None.

Submission 25-11-2015, Peer Review 26-11-2015,

Acceptance 05-12-2015, Published 12-12-2015.

Corresponding Author:

Dr. H. C. Srikantaiah,

Associate Professor, Department of General Surgery,

M. S. Ramaiah Medical College, Bangalore- 560054.

E-mail:drsrikantaiah@gmail.com

DOI:10.14260/jemds/2015/2461
Ultrasonography and Computerized tomography may be used to assist in the diagnosis of appendicitis, but are often an expensive tool in developing countries.

Even with these diagnostic aids, the rate of negative appendectomy of $15-25 \%$ has been accepted. However, the complication of unnecessary operation is $13 \%$, close to that of a genuinely inflamed appendix. Removing a normal appendix carries a mortality rate of 0.65 for every 100 operations. Prolonged clinical observation in an attempt to minimize unnecessary operations may mean a delayed operation in 28\% of cases and an unnecessary risk of perforation.

Several scoring systems have been introduced to increase the diagnostic accuracy of appendicitis with the Alvarado scoring system being the most popular. However, these were developed in the Western Countries and several studies have shown reduced sensitivity and specificity when applied to a population with a completely different ethnic origin..$^{9,10}$ A new RIPASA (Raja Isteri Penigiran Anak Saleha) scoring system was developed to aid in the diagnosis of acute appendicitis in the Asian Countries. The purpose of this study is to validate the scoring system in our setup.

\section{MATERIAL AND METHODS}

Between the years 2011 and 2013, 150 patients presenting with right iliac fossa pain abdomen were recruited into this prospective study.

\section{RESULTS}

Age distribution of the patients studied.

\begin{tabular}{|c|c|}
\hline AGE & $\begin{array}{c}\text { PERCENTAGE } \\
\text { DISTRIBUTION }\end{array}$ \\
\hline$<20$ & $15 \%$ \\
\hline $20-29$ & $39 \%$ \\
\hline $30-39$ & $31 \%$ \\
\hline $40-49$ & $8 \%$ \\
\hline $50-59$ & $5 \%$ \\
\hline$>60$ & $2 \%$ \\
\hline
\end{tabular}




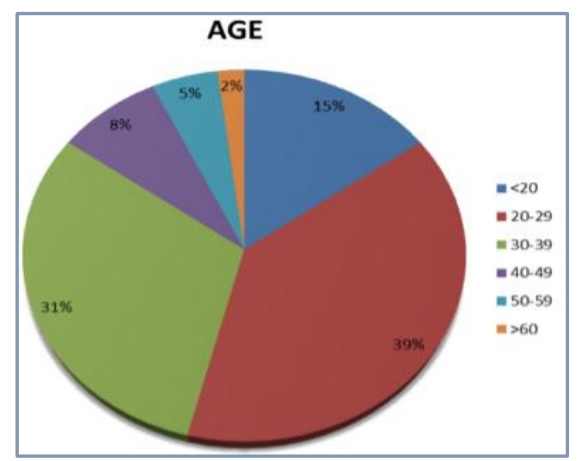

Mean age of the patients studied: 25.87.

Most common age group was between 20-29.

Gender distribution of the patients studied with 58 patients (39\%) followed by 30-39 years (31\%).

\begin{tabular}{|c|c|c|}
\hline SEX & NUMBER & PERCENTAGE \\
\hline MALE & 104 & $69 \%$ \\
\hline FEMALE & 46 & $31 \%$ \\
\hline
\end{tabular}

Our study consisted of $69 \%$ males and $31 \%$ females.
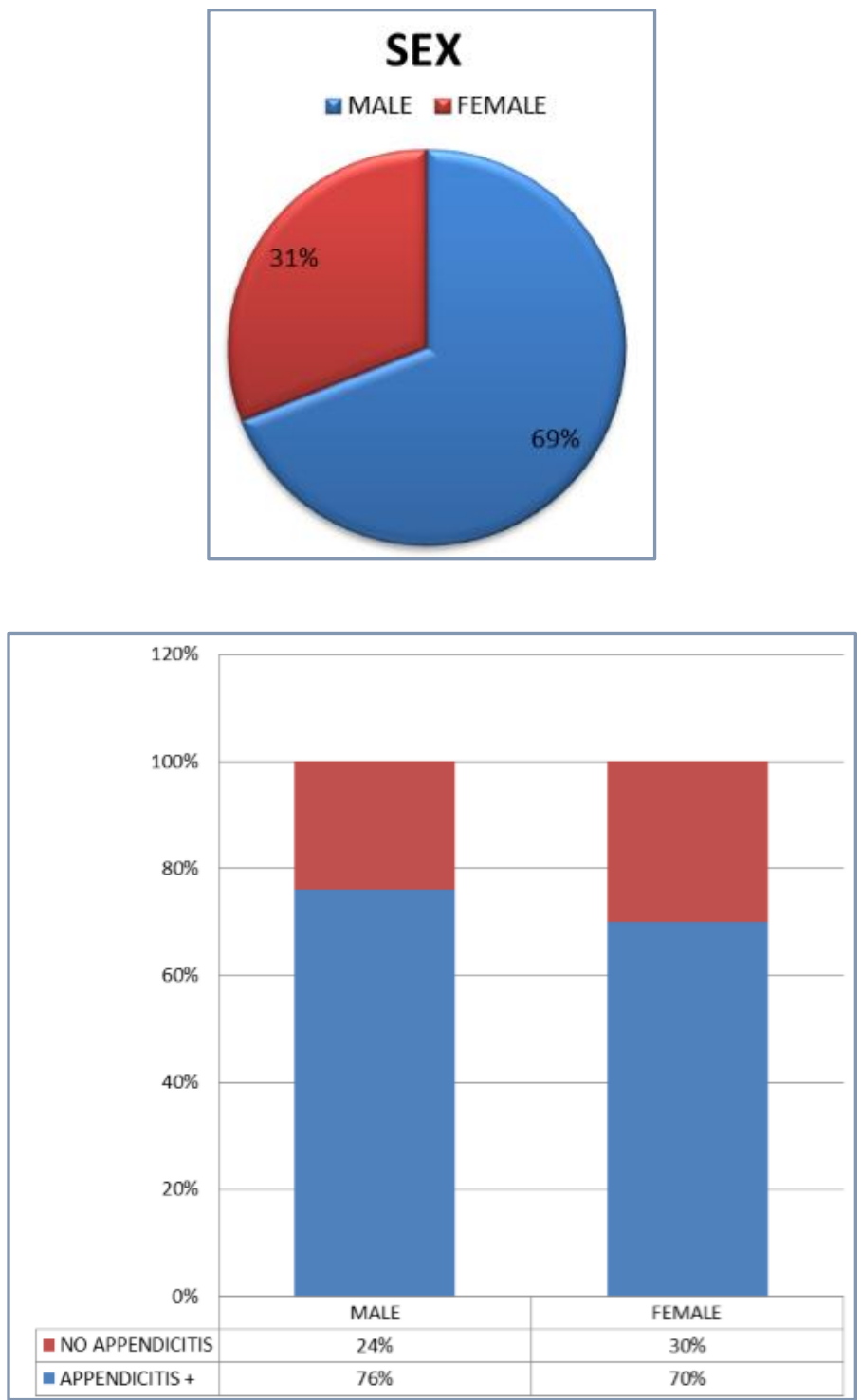

Table above shows the distribution of appendicitis among males and females.

Among 104 males in the study, 76\% (n=79) had appendicitis.

Among the 46 females, 70\% ( $\mathrm{n}=32$ ) had appendicitis.

The study included all patients presenting with RIF pain. 
Total of 150 patients in the study had right iliac fossa pain.

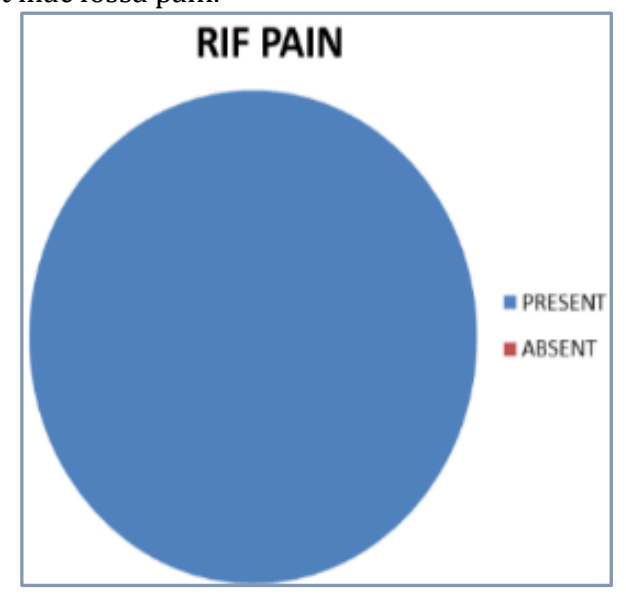

\section{MIGRATION OF PAIN}

\begin{tabular}{|c|c|c|}
\hline MIGRATION OF PAIN & NUMBER & PERCENTAGE \\
\hline PRESENT & 88 & $59 \%$ \\
\hline ABSENT & 62 & $41 \%$ \\
\hline
\end{tabular}

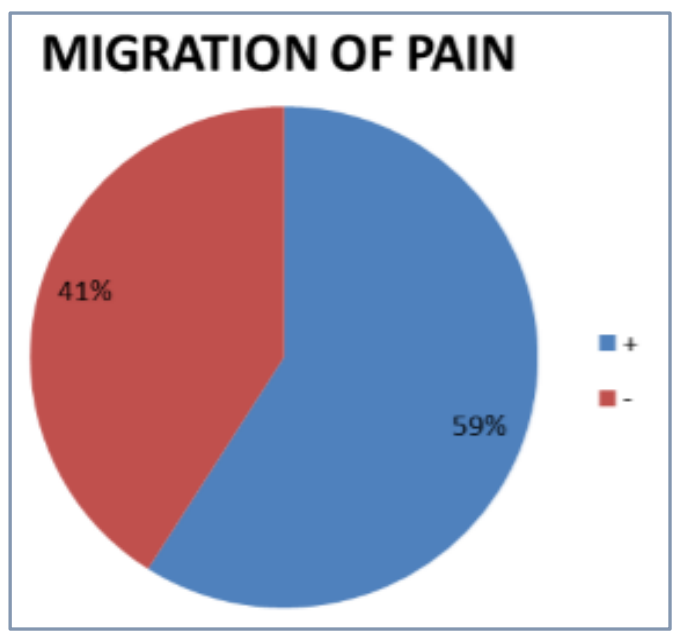

A total of $59 \%$ of the patients gave a positive history of appendicitis.

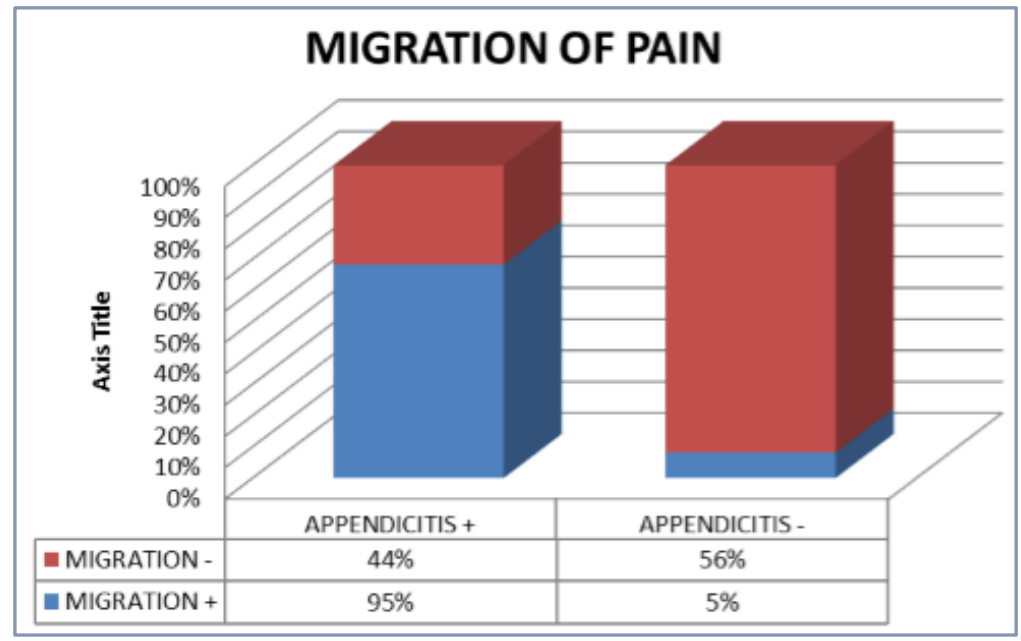

Among the 88 patients with history of migration of pain to right iliac fossa, 84 patients had appendicitis (95\%) which was statistically significant $(\mathrm{p}<0.01)$.

\section{ANOREXIA}

\begin{tabular}{|c|c|c|}
\hline ANOREXIA & NUMBER & PERCENTAGE \\
\hline PRESENT & 44 & $29 \%$ \\
\hline ABSENT & 106 & $71 \%$ \\
\hline
\end{tabular}


A total of 29\% (44) gave a positive history of anorexia.
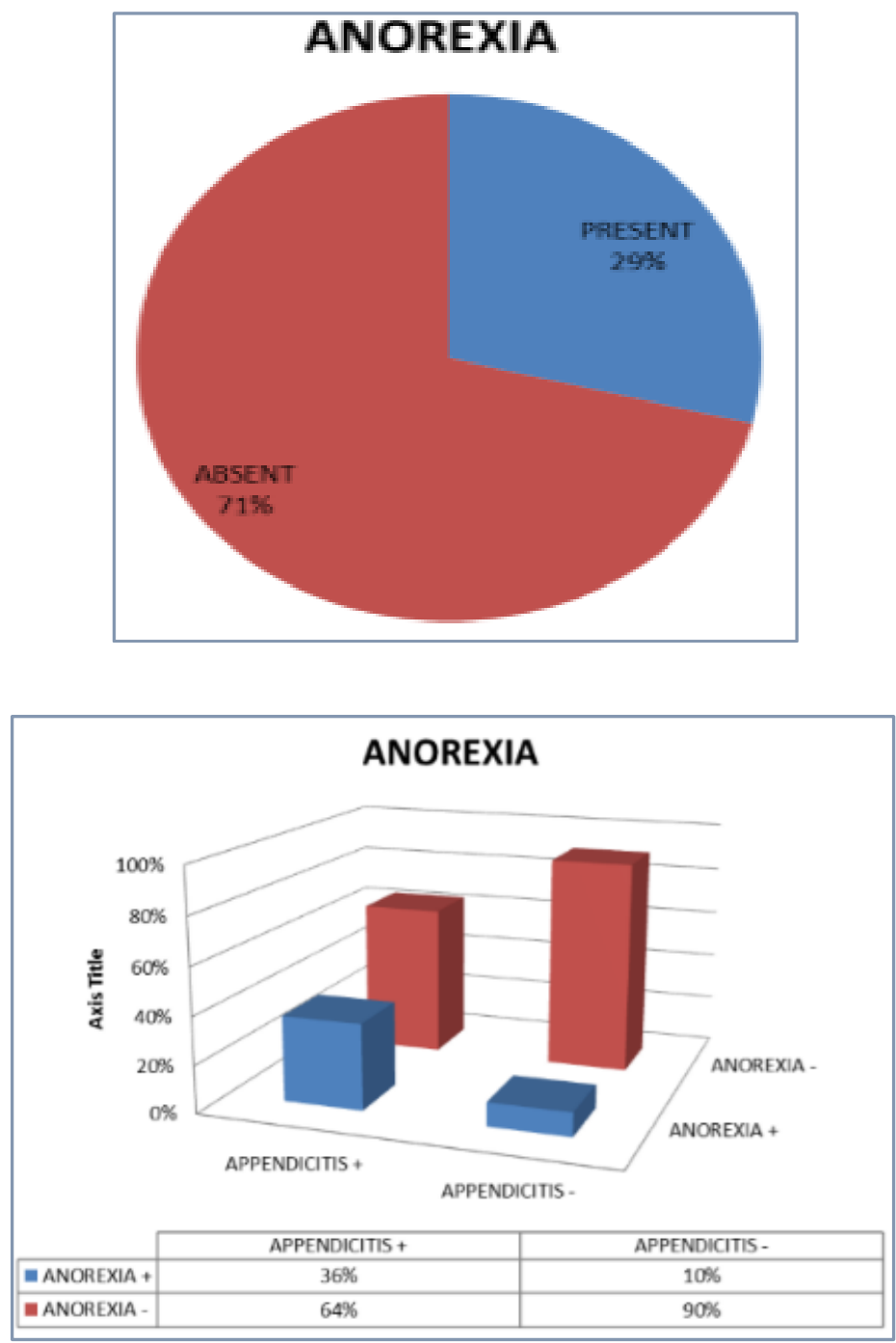

$36 \%$ of the patients with appendicitis gave a history of anorexia.

\section{NAUSEA AND VOMITING}

\begin{tabular}{|c|c|c|}
\hline NAUSEA AND VOMITING & NUMBER & PERCENTAGE \\
\hline PRESENT & 49 & 33 \\
\hline ABSENT & 101 & 71 \\
\hline
\end{tabular}

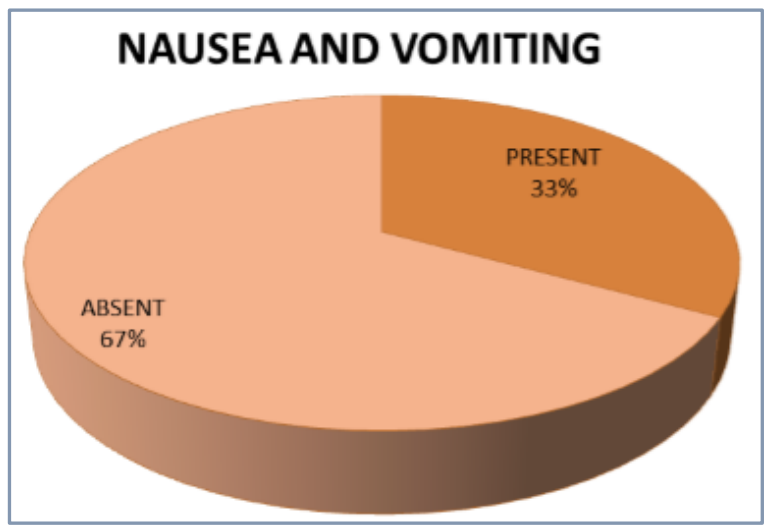

A total of 49 (33\%) of the patients gave a positive history of nausea and vomiting. 


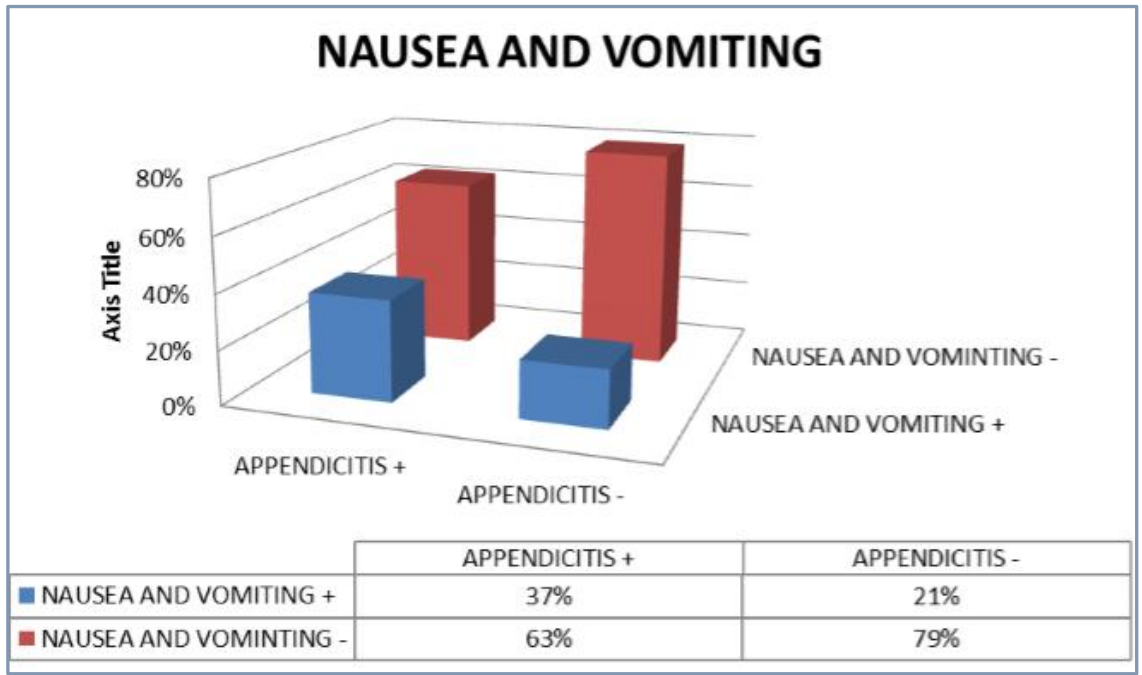

$37 \%$ of the patients with appendicitis had nausea and vomiting.

\section{DURATION OF SYMPTOMS}

\begin{tabular}{|c|c|c|}
\hline DURATION OF SYMPTOMS & NUMBER & PERCENTAGE \\
\hline$<48$ HOURS & 97 & $65 \%$ \\
\hline$>48$ HOURS & 53 & $35 \%$ \\
\hline
\end{tabular}

Among the 150 patients, $65 \%(n=97)$ presented to us with a history lasting less than 2 days.
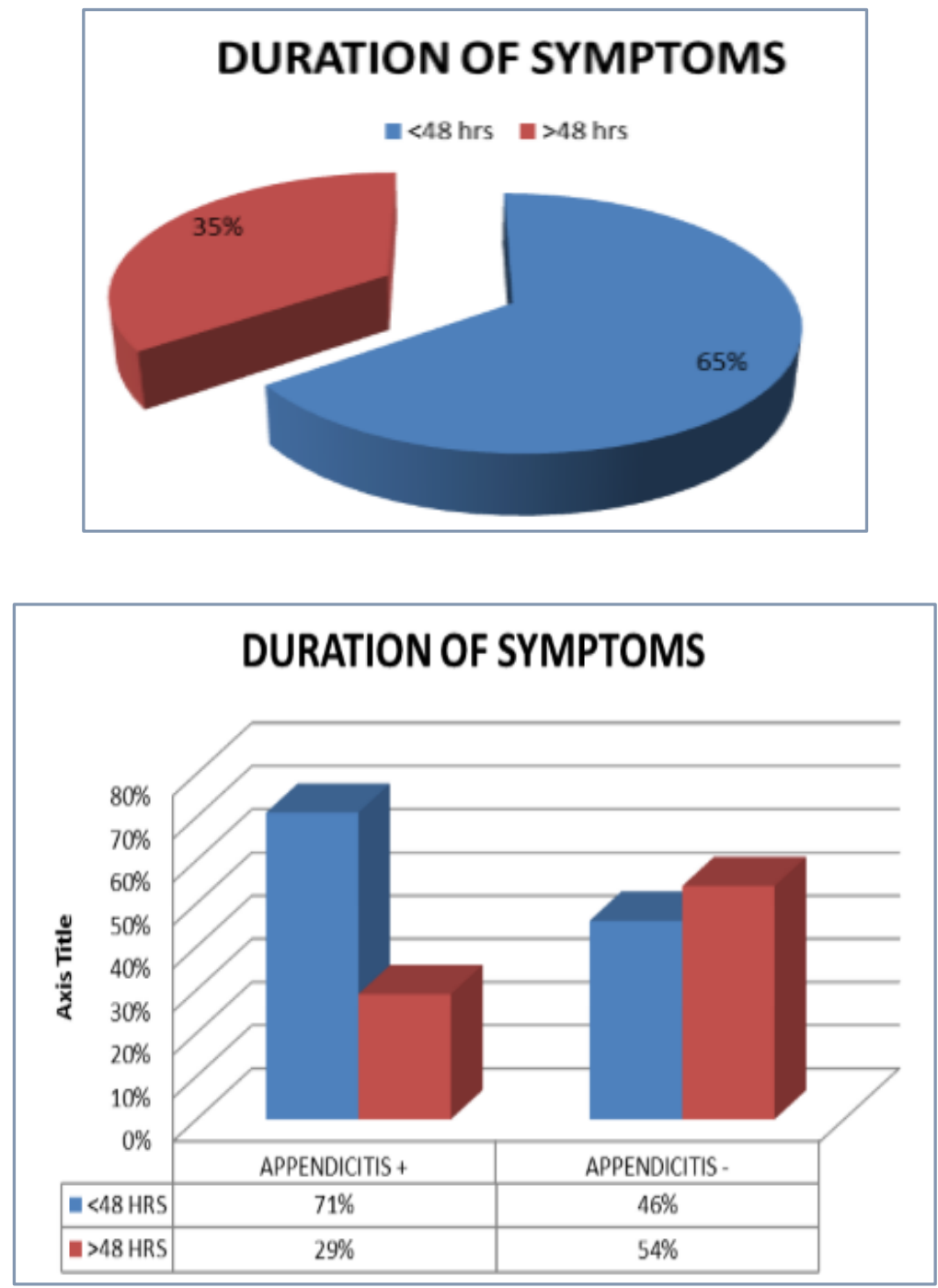

$71 \%$ of the patients with appendicitis gave history lasting less than 48 hours. 
RIGHT ILIAC FOSSA TENDERNESS

\begin{tabular}{|c|c|c|}
\hline RIF TENDERNESS & NUMBER & PERCENTAGE \\
\hline PRESENT & 134 & $89 \%$ \\
\hline ABSENT & 16 & $11 \%$ \\
\hline
\end{tabular}

\section{RIF TENDERNESS}

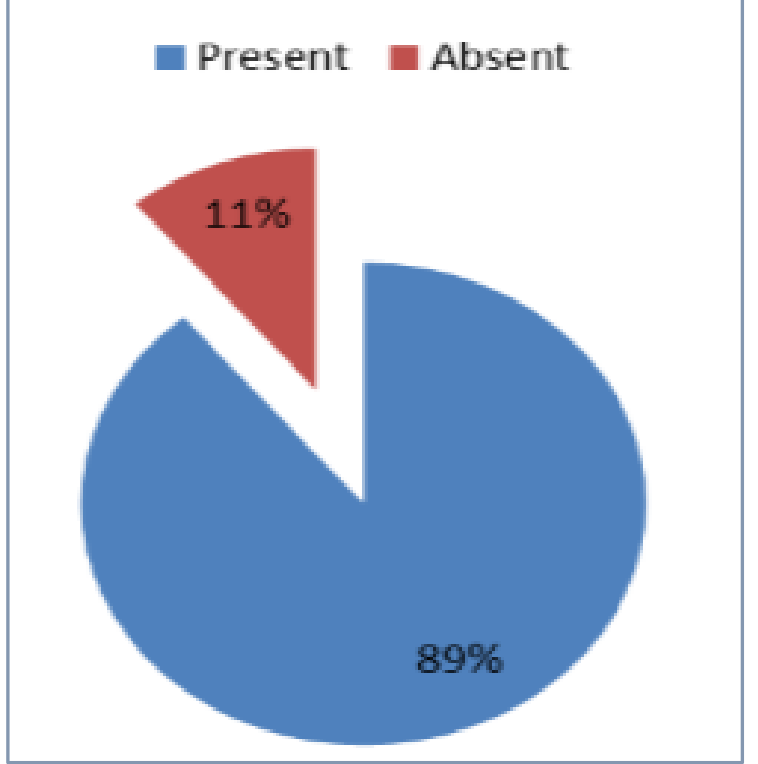

A total of 135 (89\%) patients had right iliac fossa tenderness on examination.

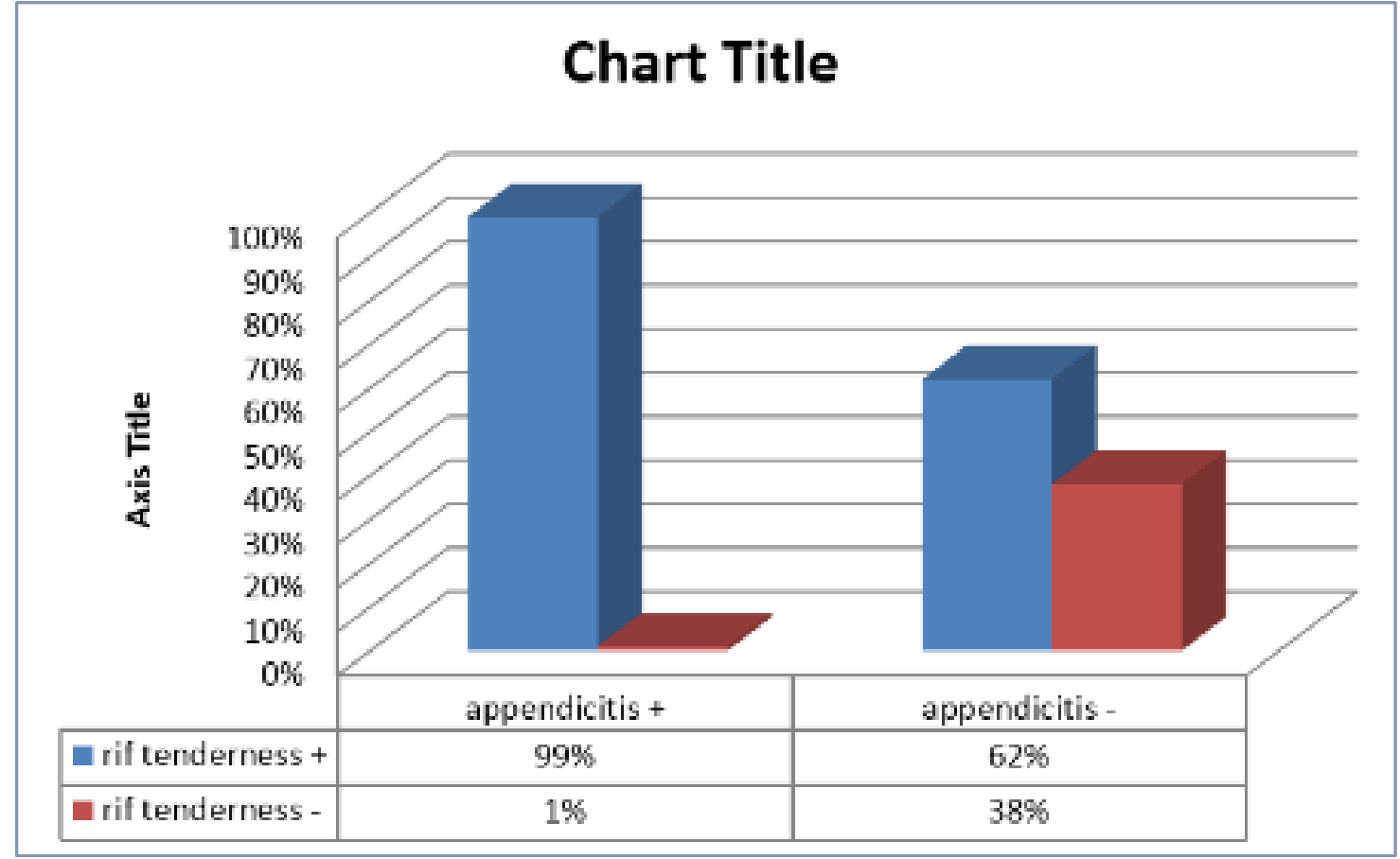

$99 \%$ of the patients with appendicitis had right iliac fossa tenderness on examination.

\section{REBOUND}

\begin{tabular}{|c|c|c|}
\hline REBOUND TENDERNESS & NUMBER & PERCENTAGE \\
\hline PRESENT & 91 & $61 \%$ \\
\hline ABSENT & 59 & $39 \%$ \\
\hline
\end{tabular}

A total of $91(61 \%)$ of the patients had rebound tenderness on examination. 

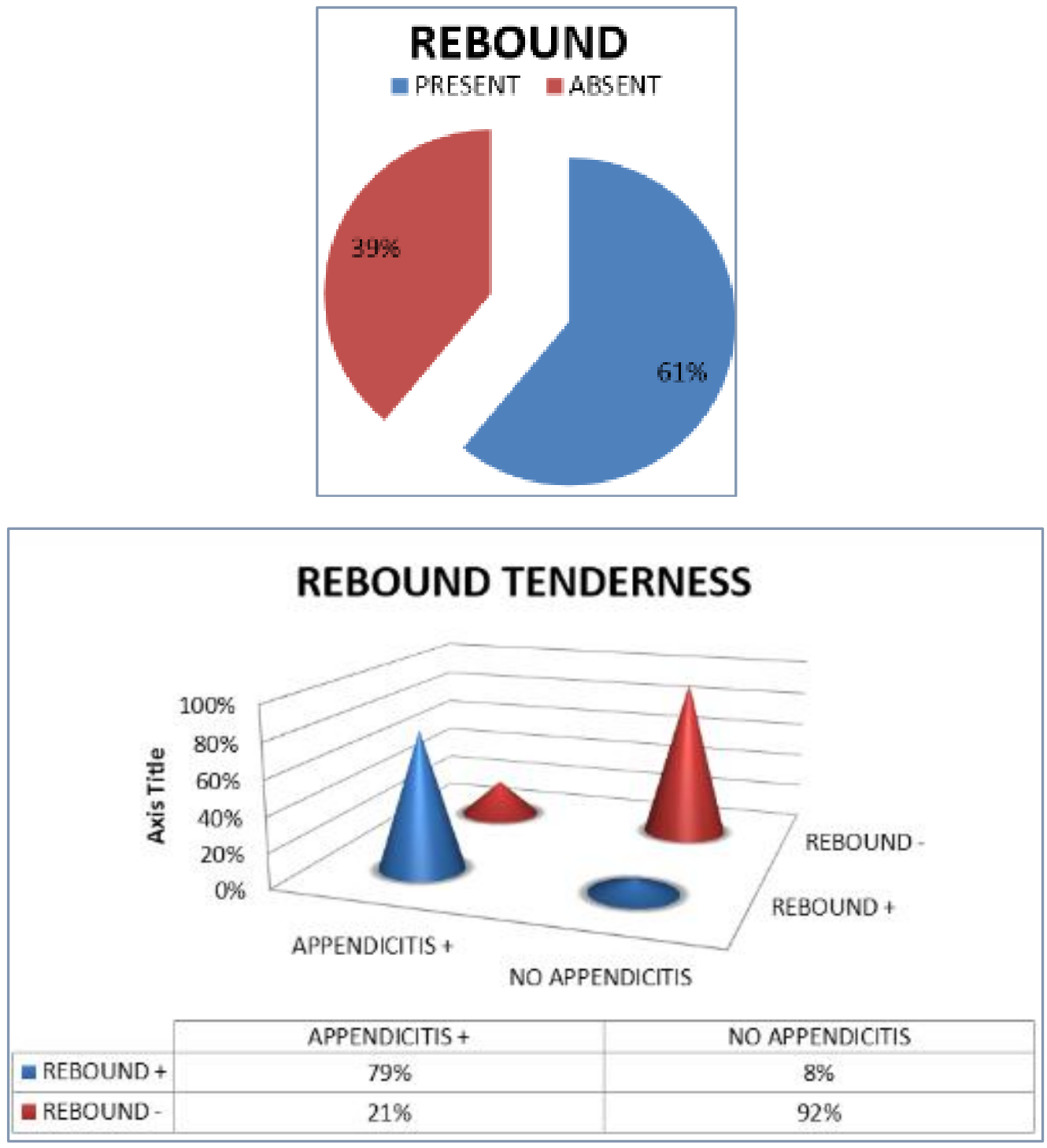

$79 \%$ of the patient's appendicitis had rebound tenderness.

FEVER

\begin{tabular}{|c|c|c|}
\hline FEVER & NUMBER & PERCENTAGE \\
\hline PRESENT & 19 & $13 \%$ \\
\hline ABSENT & 131 & $87 \%$ \\
\hline
\end{tabular}

Only $19(13 \%)$ of our patients had fever.

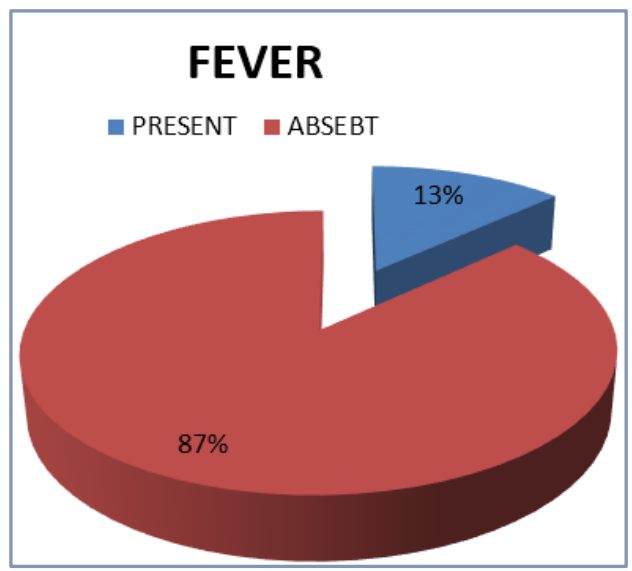




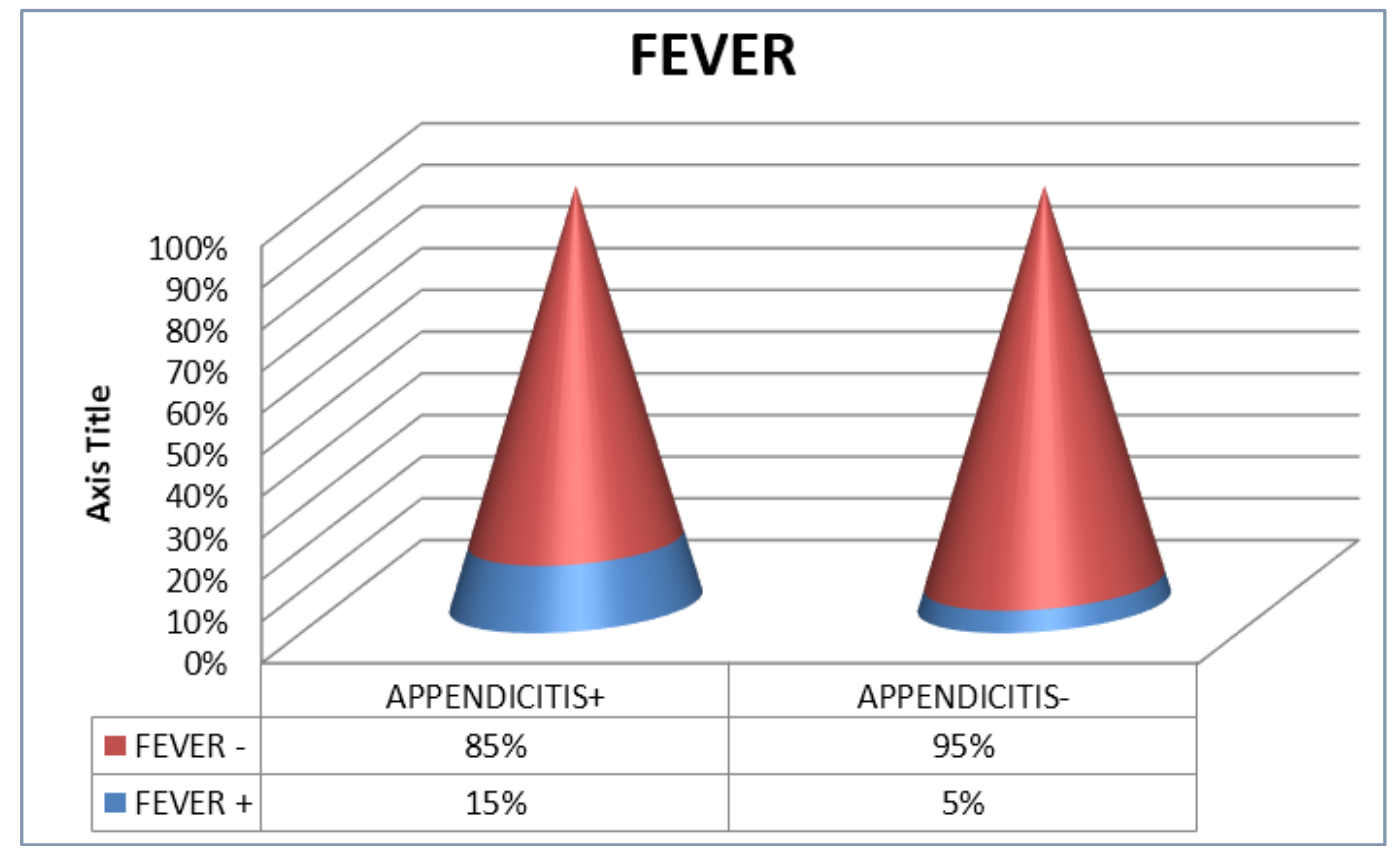

$15 \%$ of the patients with appendicitis had fever.

\section{GUARDING}

\begin{tabular}{|c|c|c|}
\hline GUARDING & NUMBER & PERCENTAGE \\
\hline PRESENT & 26 & $17 \%$ \\
\hline ABSENT & 124 & $83 \%$ \\
\hline
\end{tabular}

A total of 26 patients (17\%) had guarding.

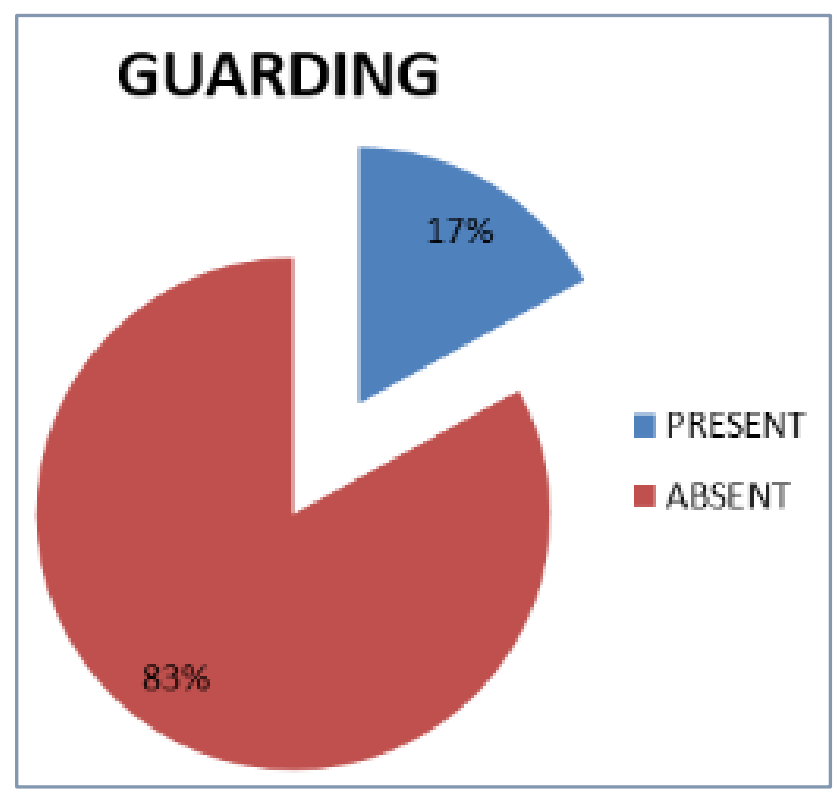

All the patients with guarding and RIF tenderness had appendicitis. Only $23 \%$ of the patients with appendicitis had guarding.

\section{ROVSING'S SIGN}

\begin{tabular}{|c|c|c|}
\hline ROVSING'S SIGN & NUMBER & PERCENTAGE \\
\hline PRESENT & 45 & $30 \%$ \\
\hline ABSENT & 105 & $70 \%$ \\
\hline
\end{tabular}

45 patients (30\%) had Rovsing's sign positive on examination. 

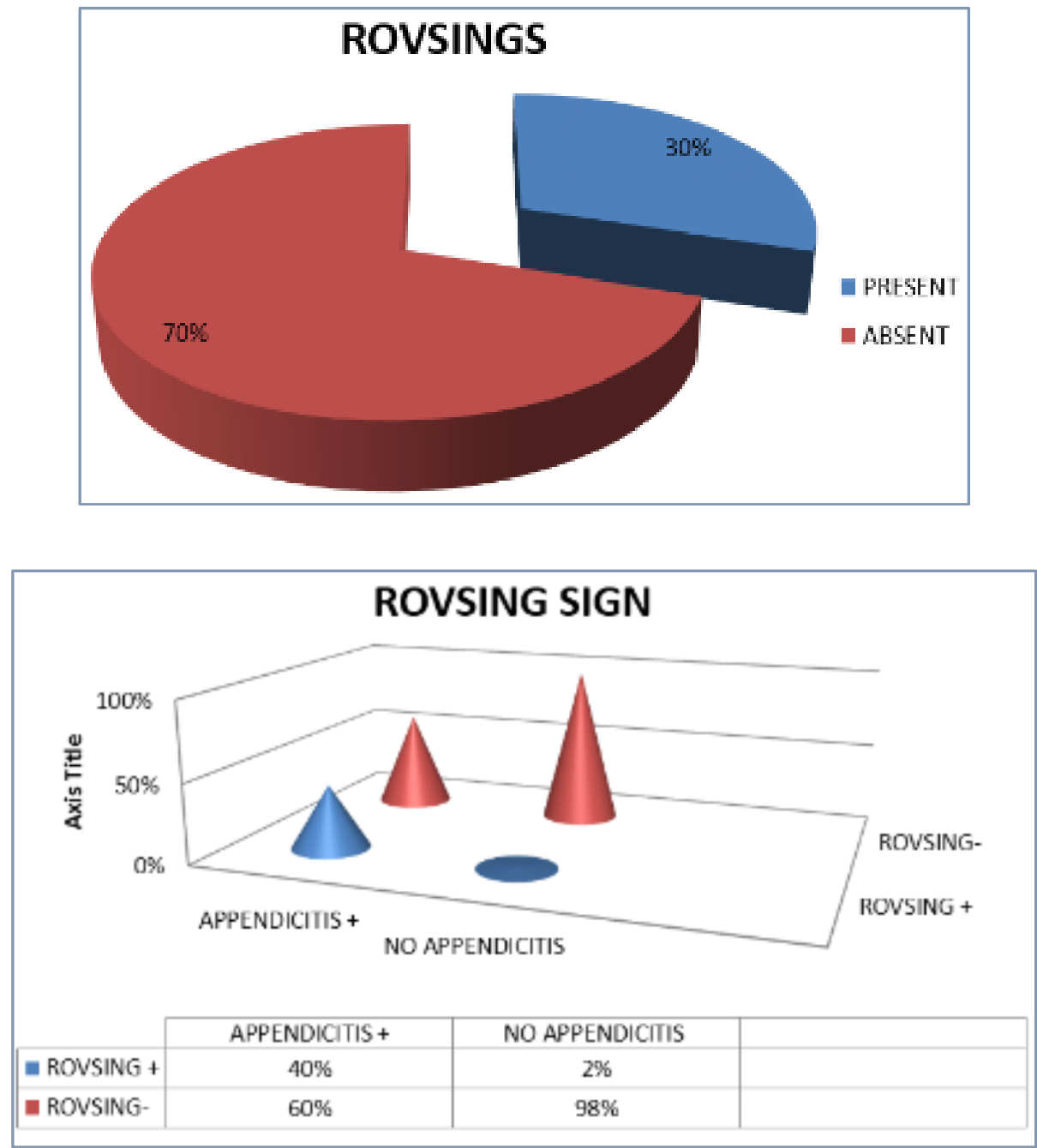

$40 \%$ of the patients with appendicitis had Rovsing's sign positive.

\section{INVESTIGATIONS}

RAISED TOTAL COUNT

\begin{tabular}{|c|c|c|}
\hline RAISED TC & NUMBER & PERCENTAGE \\
\hline$<11000$ & 37 & 25 \\
\hline$>11000$ & 113 & 75 \\
\hline
\end{tabular}

113 patient's (75\%) had a total count more than 11,000 .

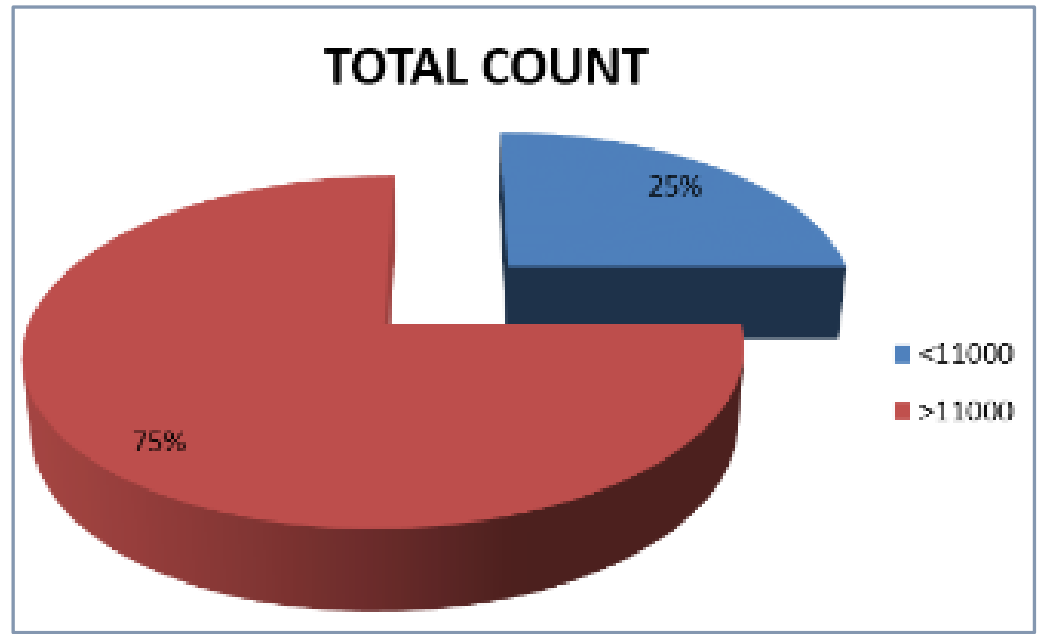




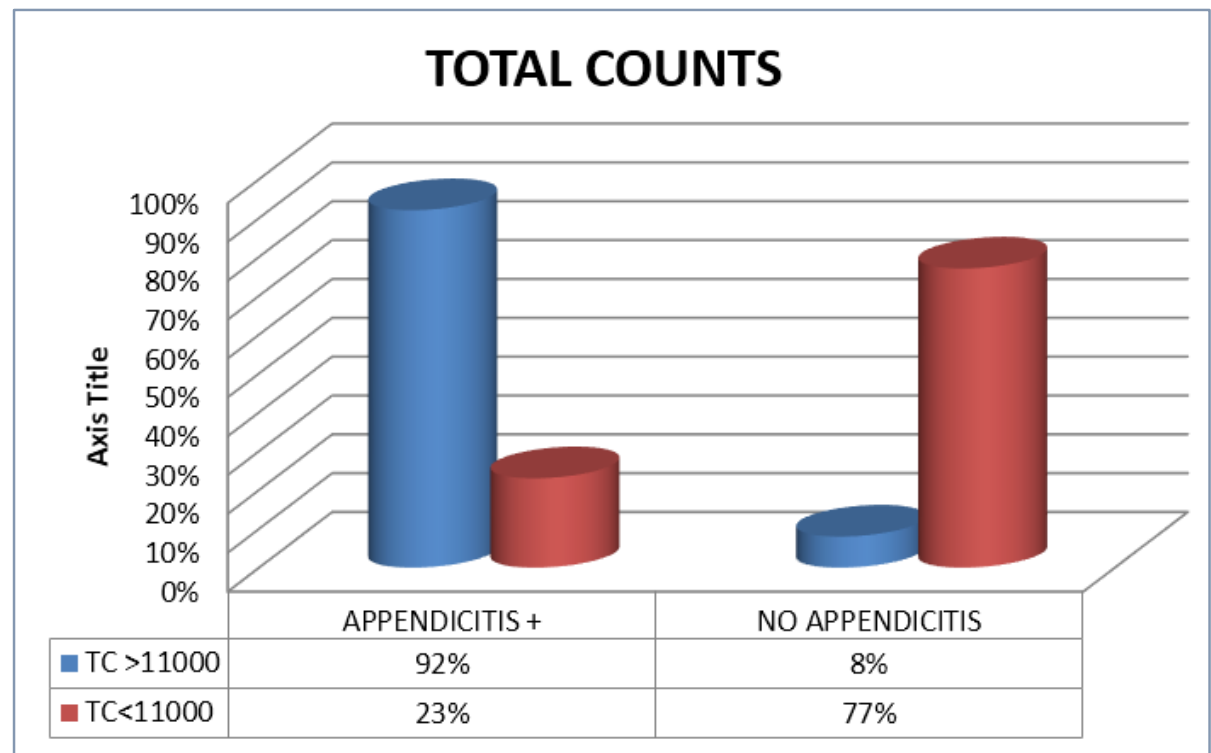

$92 \%$ of patients with appendicitis had raised TC.

\section{SHIFT TO LEFT}

\begin{tabular}{|c|c|c|}
\hline SHIFT TO LEFT & NUMBER & PERCENTAGE \\
\hline PRESENT & 108 & 72 \\
\hline ABSENT & 42 & 28 \\
\hline
\end{tabular}

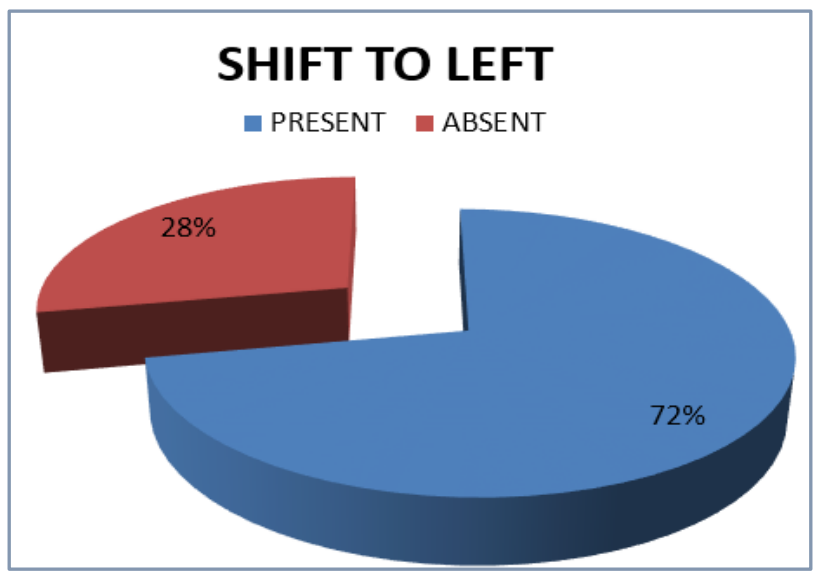

URINE ANALYSIS

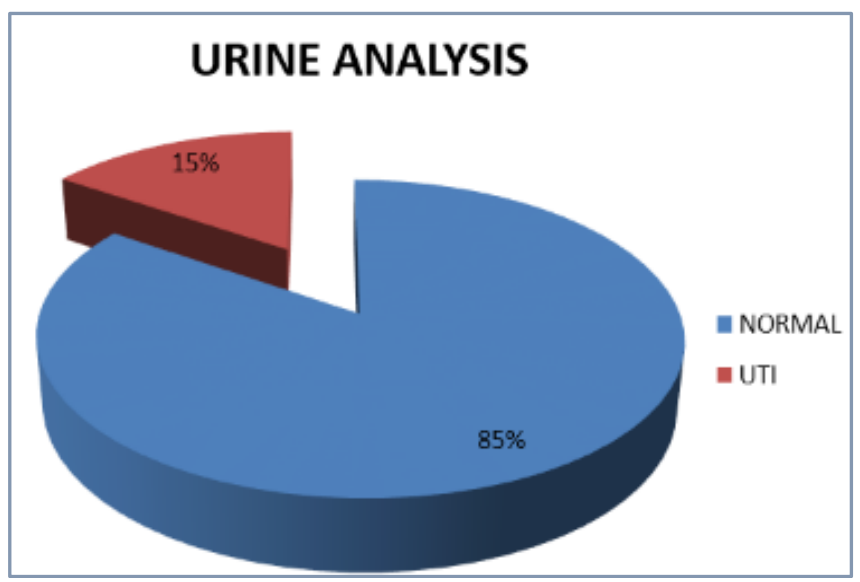




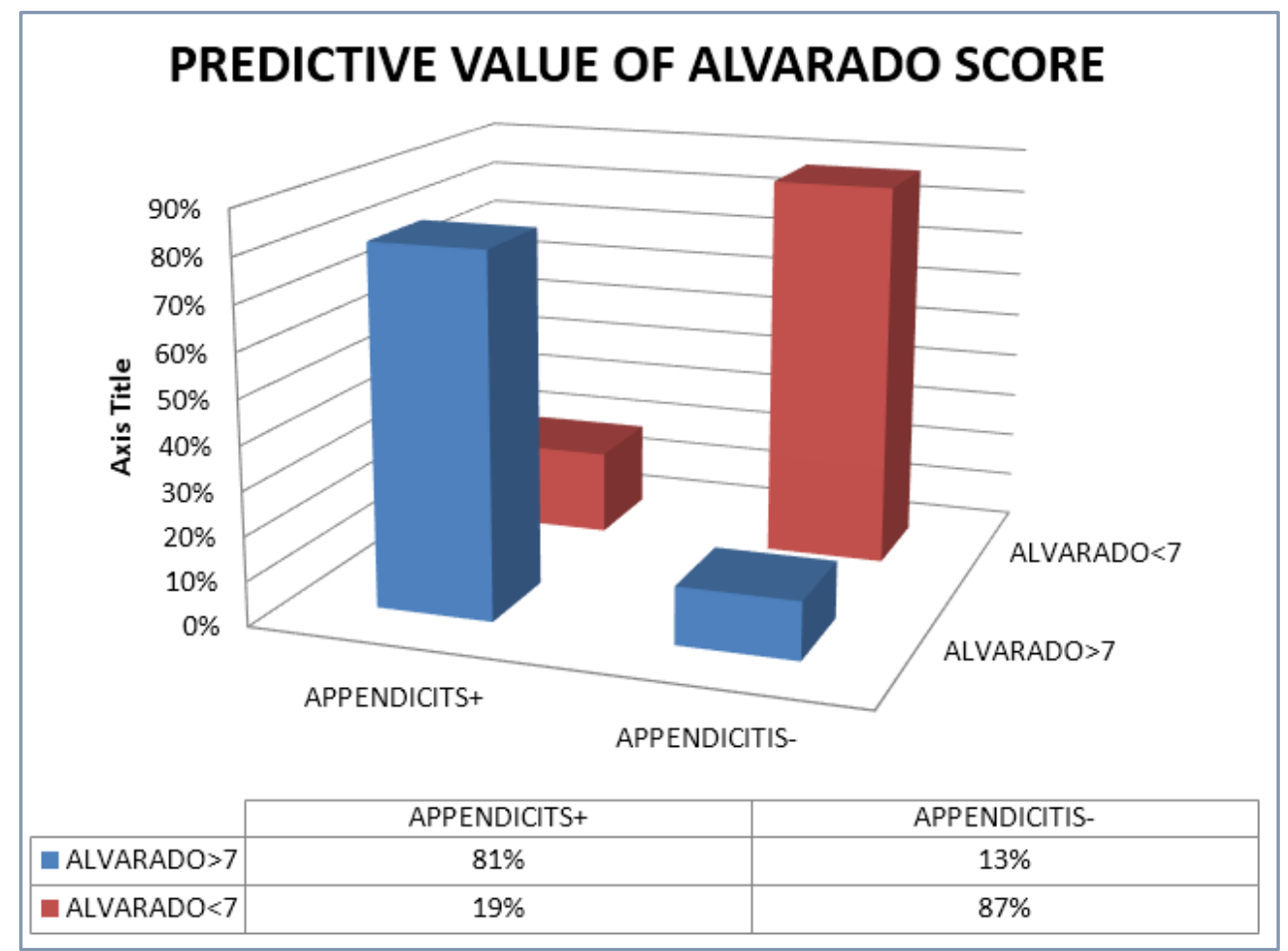

The Alvarado score was able to pick up 90 (81\%) of the 111 cases diagnosed with appendicitis.

The Alvarado score has,

True positive rate of $81 \%$,

True negative rate of $87 \%$,

False positive rate of $19 \%$,

False negative rate of $13 \%$.

The sensitivity of Alvarado score is $81.1 \%$ and specificity is $87.2 \%$.

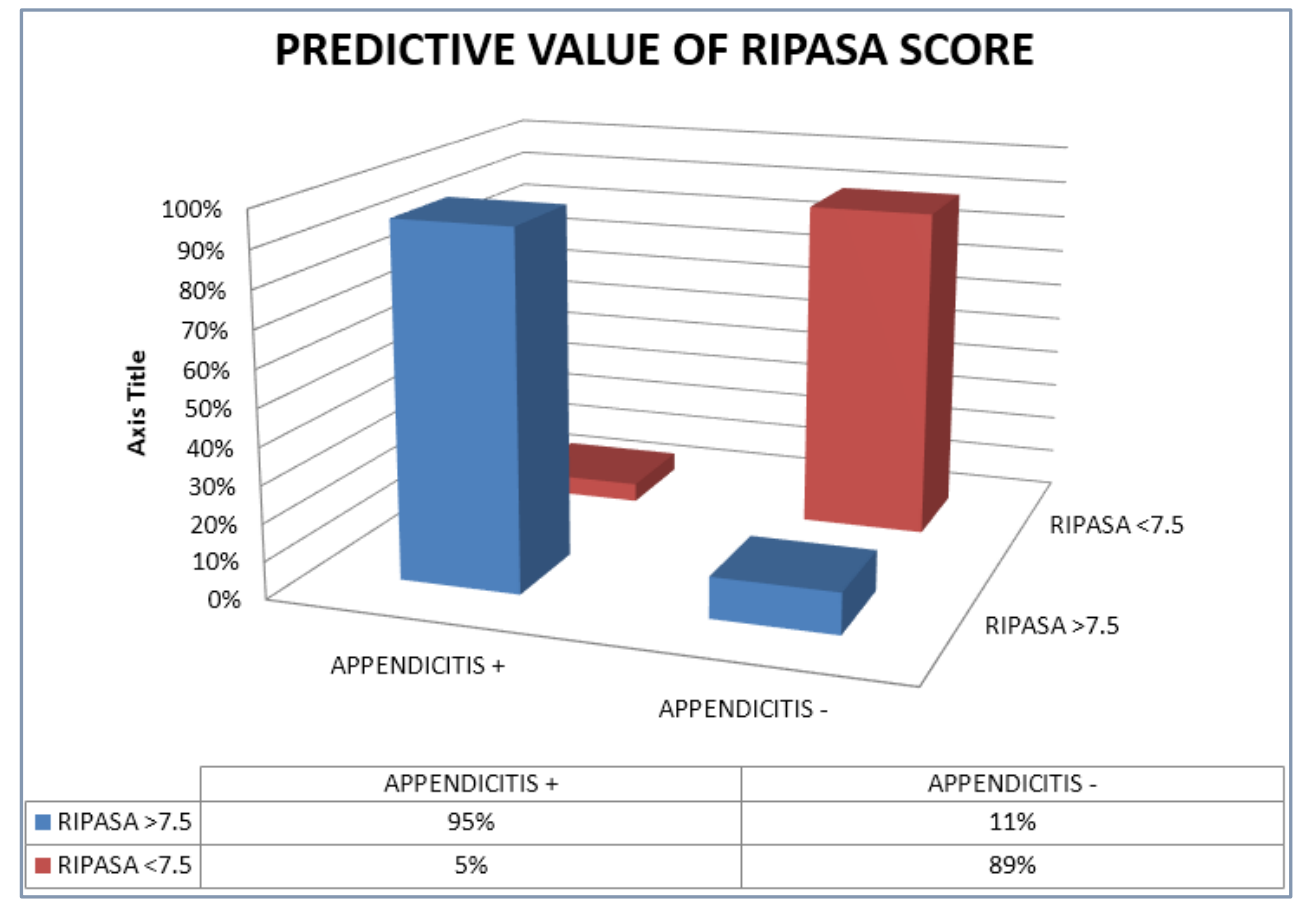

The RIPASA (Raja Isteri Pengiran Anak Saleha) score was able to pick up 106(95\%) of the 111 cases of appendicitis.

The RIPASA (Raja Isteri Pengiran Anak Saleha) score has,

True positive rate of $95 \%$.

True negative rate of $89 \%$.

False positive rate of $5 \%$.

False negative rate of $11 \%$. 
The sensitivity of RIPASA score is $95.5 \%$.

The specificity of RIPASA score is $89.7 \%$.

This figure shows the ROC curve for both RIPASA and Alvarado scoring systems.

The area covered under the RIPASA score, $92.6 \%$ is greater than that of the Alvarado score $84 \%$ which is statistically significant $(\mathrm{p}<0.001)$.

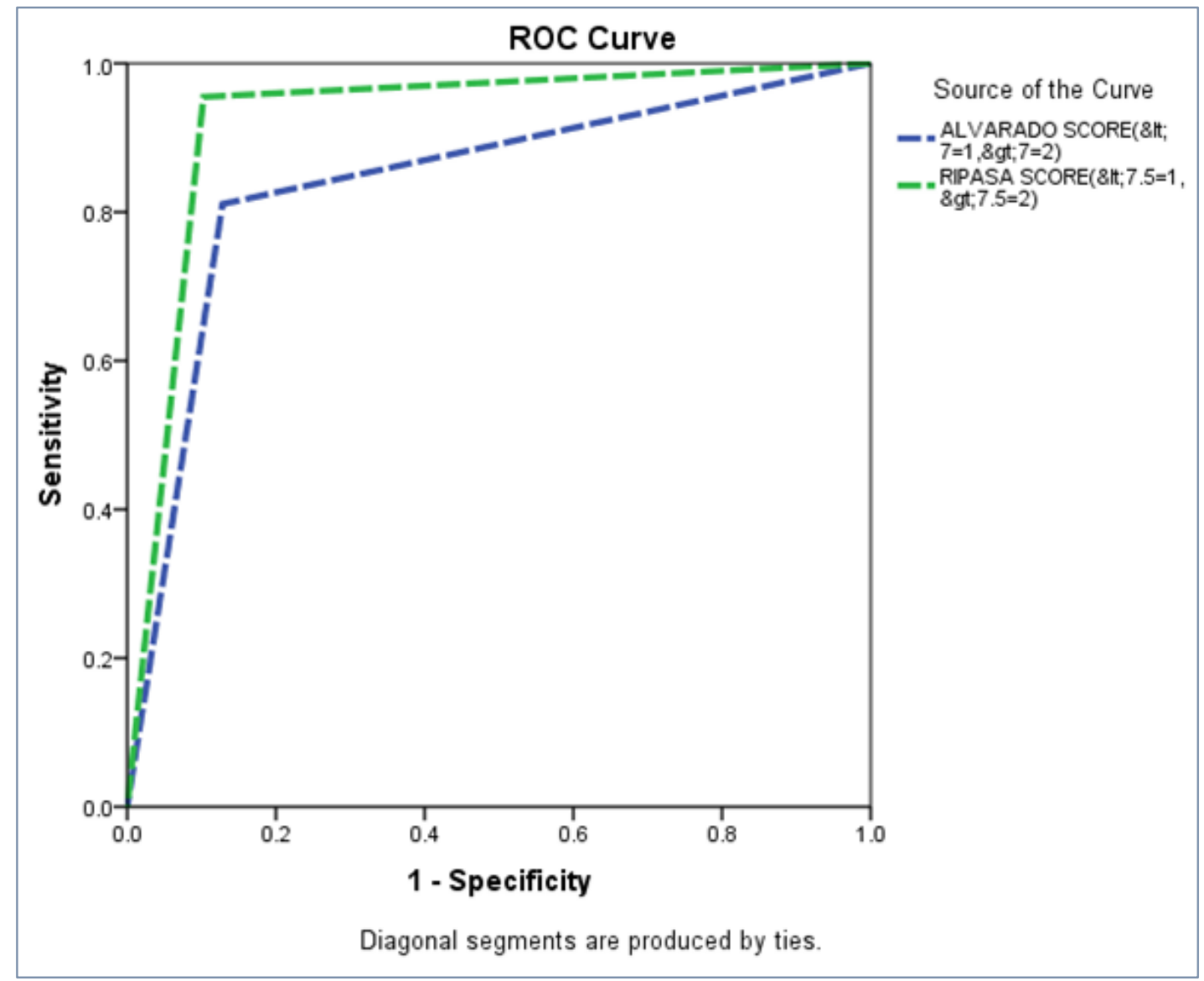

Area under the Curve

\begin{tabular}{|c|c|c|c|c|c|}
\hline \multirow{2}{*}{$\begin{array}{c}\text { Test Result } \\
\text { Variable(s) }\end{array}$} & Area & \multirow{2}{*}{ Std. Error } & \multirow{2}{*}{ Asymptotic Sig. ${ }^{\text {b }}$} & \multicolumn{2}{|c|}{$\begin{array}{c}\text { Asymptomatic 95\% } \\
\text { Confidence Interval }\end{array}$} \\
\cline { 3 - 6 } & & & & $\begin{array}{c}\text { Lower } \\
\text { Bound }\end{array}$ & $\begin{array}{c}\text { Upper } \\
\text { Bound }\end{array}$ \\
\hline ALVARADO SCORE (\&lt;7=1,\&gt;7=2) & .841 & .038 & .000 & .767 & .916 \\
\hline RIPASA SCORE (\&lt;7.5=1,\&gt;7.5=2) & .926 & .031 & .000 & .866 & .986 \\
\hline
\end{tabular}

\section{DISCUSSION}

A total of 150 patients with right iliac fossa pain undergoing appendectomy were recruited into the study based on the inclusion and exclusion criteria mentioned earlier.

The most common age group in this study was $20-29$ years (39\%) followed by $30-39$ years (31\%) with a mean age of 25.87 years. Most of the patients, $69 \%$ in this study were males. The mean age and sex incidence was in agreement with the study by Chong et al. (25.1 years).

The Alvarado scoring system had a sensitivity and specificity of $81.1 \%$ and $87.2 \%$ for the diagnosis of acute appendicitis, which was statistically significant $(\mathrm{p}<0.001)$. 


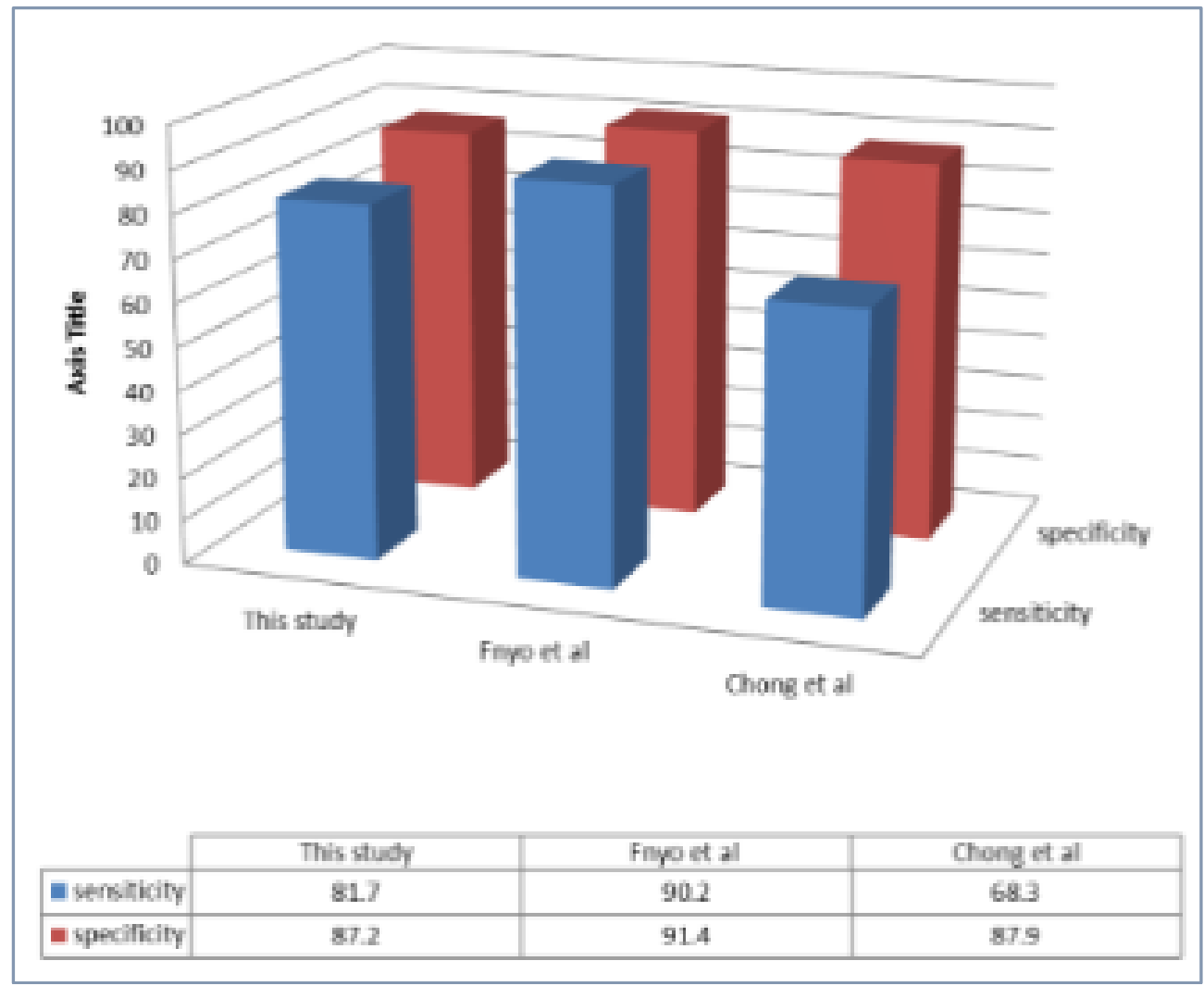

The sensitivity and specificity of the Alvarado score compared with the studies conducted by Chong et al. and Fenyo et al. is as shown. The specificity is in agreement with the 2 studies, but the sensitivity compared to Fenyo et al. is less but better than the sensitivity as per Chong et al.

The positive predictive value for the diagnosis of appendicitis was $81 \%$ and negative predictive value was $87 \%$.

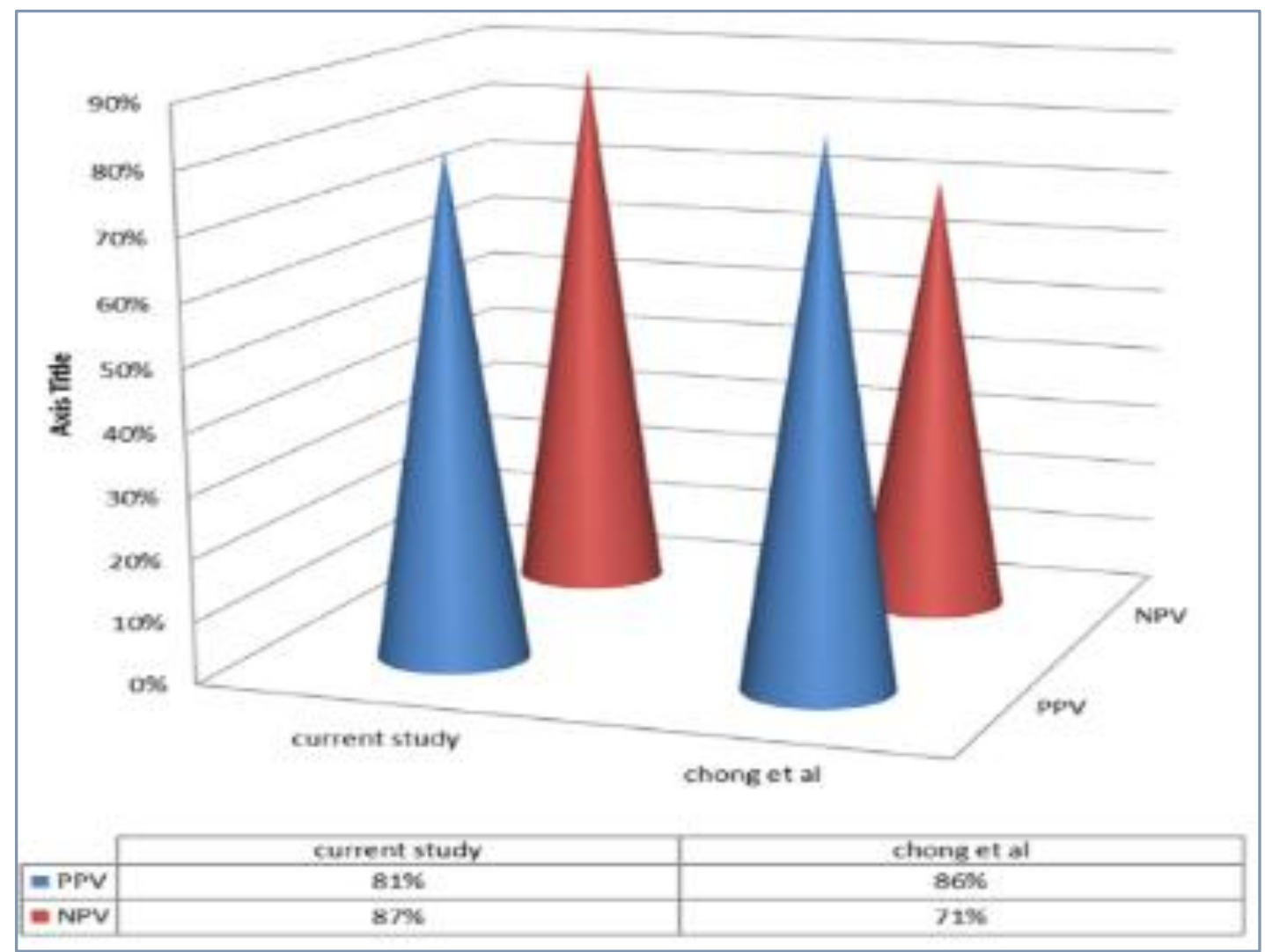

RIPASA score in this study had a sensitivity of $95.5 \%$ and a specificity of $89.7 \%$, it was in agreement with the study conducted by Chong et al. 


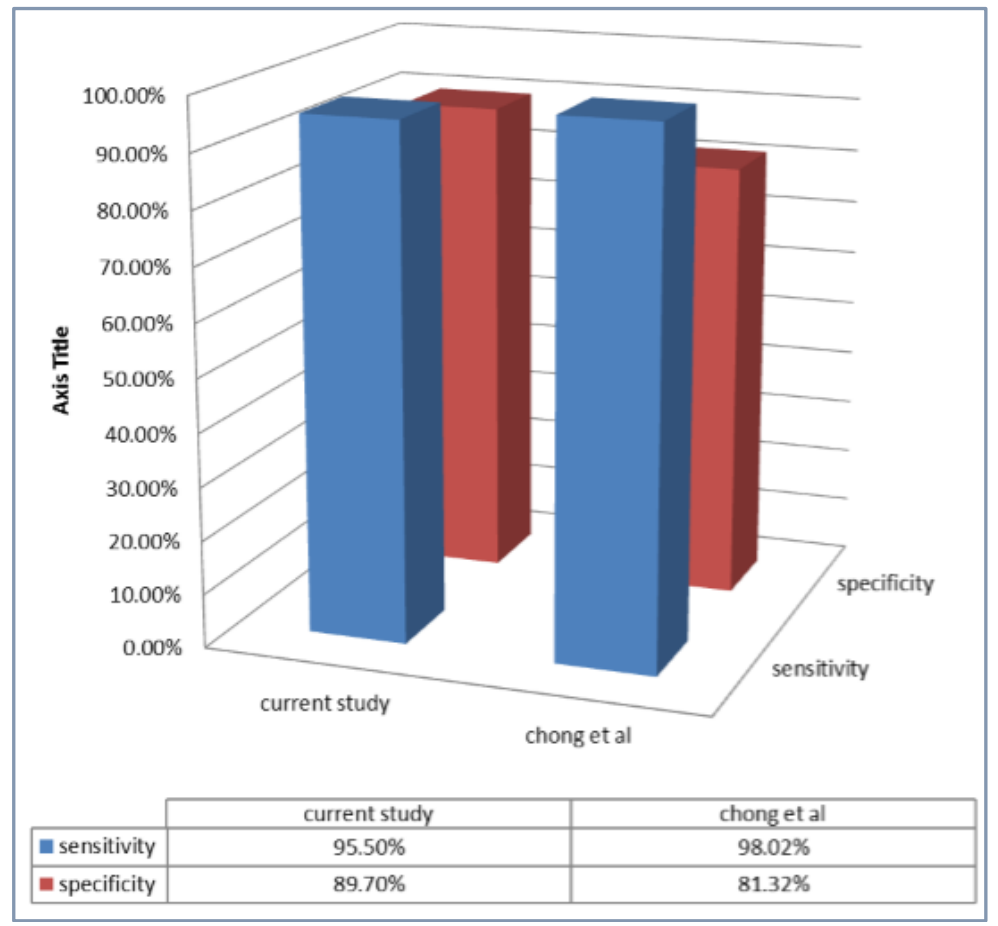

The positive predictive value was $95 \%$ and negative predictive value was found to be $89 \%$. This is compared to the study by Chong et al.

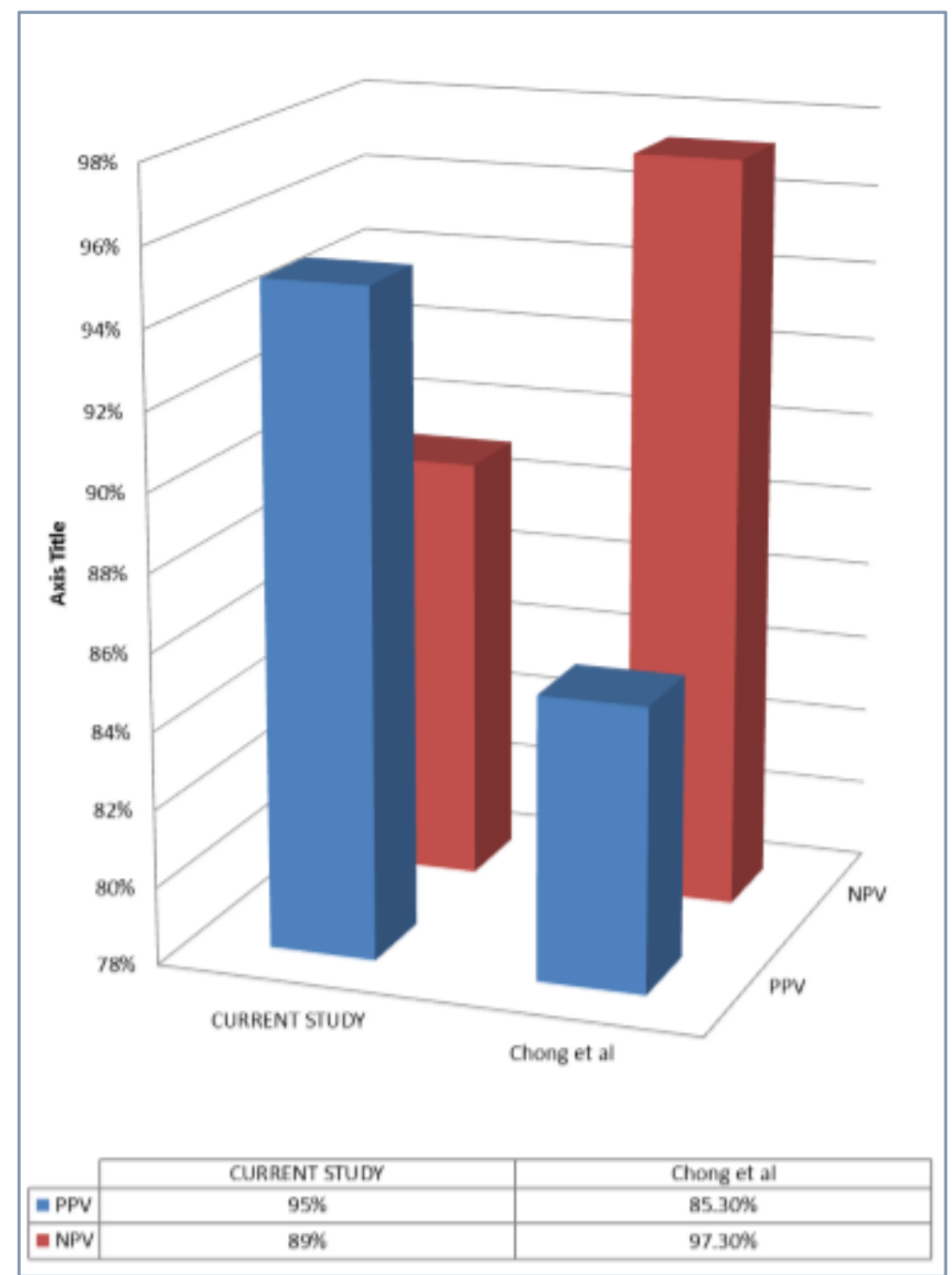

The ROC curve was compared with the study by Chong et al. 

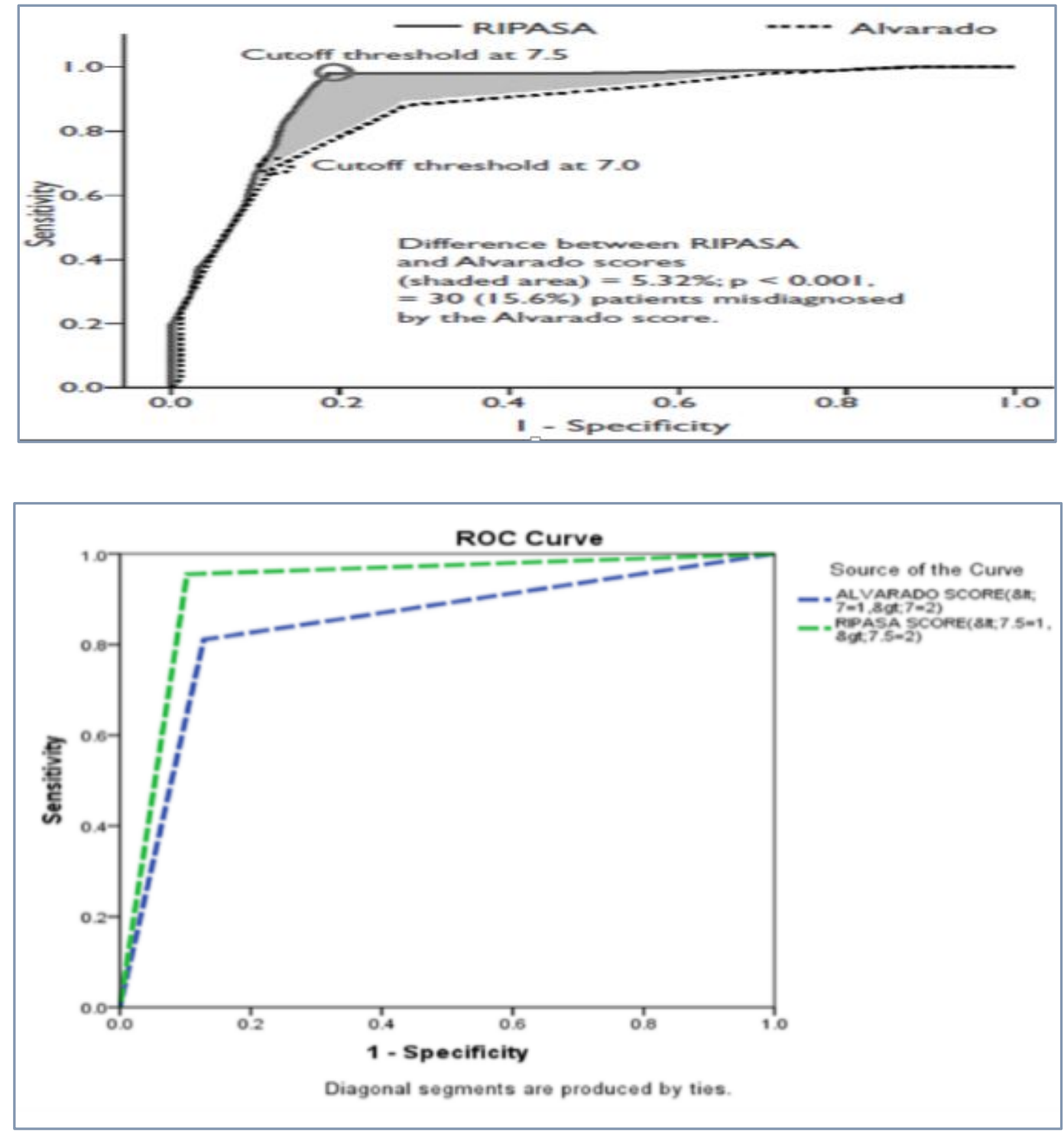

The difference in the area covered by the 2 scoring systems in this study equates to $8.6 \%$ and to $5.3 \%$ in the study by Chong et al. This confirms that RIPASA scoring system is better than Alvarado scoring system for the diagnosis of acute appendicitis.

\section{CONCLUSION}

RIPASA scoring system is an easy and reliable diagnostic tool for the diagnosis of acute appendicitis.

RIPASA scoring system is better than Alvarado scoring system for the diagnosis of acute appendicitis.

\section{ACKNOWLEDGEMENT}

Authors acknowledge the immense help received from the scholars, whose articles are cited and included in the references of this manuscript. The authors are also grateful to authors/editors/publishers of all those articles, journals and books from where the literature for this article has been reviewed and discussed.

\section{REFERENCES}

1. James $M$ Wagner, et al. Does the patient have appendicitis? JAMA 1996;276:1589-1594.

2. Owens TD, Williams $\mathrm{H}$, Stiff $\mathrm{G}$, et al. Evaluation of the Alvarado score in acute appendicitis. J R Soe Med 1992;85:87-89.

3. Balsano N, Cayten CG. Surgical emergencies of the abdomen. Emerg Med. Clinic North Am 1990;8:399-410.
4. Lewis FR, Hocroft JW, Boey J, et al. Appendicitis. A critical Review of diagnosis and treatment in 100 cases. Arch Surg 1975;110:677-684.

5. Addiss DG, Shaffer N, Fowler BS. The epidemiology of appendicitis and appendectomy in United States. American Journal Epidemiology, 1990;132:910-925.

6. Muller BA, Dailing JR, Moore DE, et al. Appendectomy and the risk of tubal infertility. Eng J Med 1986;315:1506-1509.

7. Kalan M, Rich AJ, Talbot D. Evaluation of the modified Alvarado score in diagnosis of acute appendicitis: A prospective study. BJ Radiology, 63, 787-79.

8. Verma, Metha FS, Vyas $\mathrm{KC}$, et al. C reactive protein in acute appendicitis; Indian Journal of Surgery 1995;57(8):238-240.

9. Chong CF, Adi MIW, Thien A, et al. Development of the RIPASA score: a new appendicitis scoring system for the diagnosis of acute appendicitis: Singapore Med J 2010;51(3):220.

10. Richard A Williams, Paul Myers. Monograph Pathology of the Appendix, first edition, Chapman and Hall Inc. 1994. 